\title{
Correction to: Pool Fires in Chemical Process Industries: Occurrence, Mechanism, Management
}

Vipin - S. K. Pandey - S. M. Tauseef - Tasneem Abbasi • S. A. Abbasi

Published online: 9 August 2018

(c) ASM International 2018

\section{Correction to: J Fail. Anal. and Preven.}

https://doi.org/10.1007/s11668-018-0517-2

In the original version of this article, Vipin's name was incorrect. It is correct as reflected here. The original article has also been corrected.

The original article can be found online at https://doi.org/10.1007/ s11668-018-0517-2.

Vipin · S. K. Pandey · T. Abbasi · S. A. Abbasi $(\bowtie)$

Centre for Pollution Control and Environmental Engineering, Pondicherry University, Chinakalapet, Puducherry 605 014,

India

e-mail: abbasi.cpee@gmail.com

S. M. Tauseef

Environmental Research Institute, University of Petroleum and

Energy Studies, Dehradun 248 007, India 